Article

\title{
Genome-Wide Identification and Expression Profile Analysis of the NF-Y Transcription Factor Gene Family in Petunia hybrida
}

\author{
Qian Wei ${ }^{1,+} \mathbb{D}$, Shiyun Wen ${ }^{1,+}$, Chuying Lan ${ }^{1}$, Yixun $\mathrm{Yu}^{1}{ }^{1}$ and Guoju Chen ${ }^{2, *}$ \\ 1 Guangdong Key Laboratory for Innovative Development and Utilization of Forest Plant Germplasm, \\ College of Forestry and Landscape Architecture, South China Agricultural University, Guangzhou 510642, \\ China; weiqian@scau.edu.cn (Q.W.); sywen@stu.scau.edu.cn (S.W.); cylan@stu.scau.edu.cn (C.L.); \\ yuyixun@scau.edu.cn (Y.Y.) \\ 2 College of Horticulture, South China Agricultural University, Guangzhou 510642, China \\ * Correspondence: gjchen@scau.edu.cn; Tel.: +86-020-8528-2126 \\ + These authors contributed equally to this work.
}

Received: 9 February 2020; Accepted: 3 March 2020; Published: 6 March 2020

\begin{abstract}
Nuclear Factor Ys (NF-Ys) are a class of heterotrimeric transcription factors that play key roles in many biological processes, such as abiotic stress responses, flowering time, and root development. The petunia (Petunia hybrida) is a model ornamental plant, and its draft genome has been published. However, no details regarding the NF-Y gene family in petunias are available. Here, 27 NF-Y members from the petunia genome were identified, including 10 PhNF-YAs, 13 PhNF-YBs, and 4 PhNF-YCs. Multiple alignments showed that all PhNF-Y proteins had clear conserved core regions flanked by non-conserved sequences. Phylogenetic analyses identified five pairs of orthologues NF-YB proteins from Petunia and Arabidopsis, and six pairs of paralogues NF-Y proteins in Petunia. Analysis of the gene structure and conserved motifs further confirmed the closer relationship in each subfamily. Bioinformatics analysis revealed that 16 PhNF-Ys could be targeted by 18 miRNA families. RNA-seq results showed that expression patterns of PhNF-Ys among four major organs (leaf, stem, flower, and root) were clustered into six major groups. The stress response pattern of PhNF-Ys was identified under cold, heat, drought, and salinity treatments. Based on the RNA-seq data, we found that 3 genes responded to drought, 4 genes responded to salt, 10 genes responded to cold, and 9 genes responded to hot. In conclusion, this study provides useful information for further studying the functions of NF-YS in stress response.
\end{abstract}

Keywords: Petunia hybrida; NF-Y gene family; gene expression; abiotic stress

\section{Introduction}

Abiotic stress, such as temperature, salinity, and drought, can cause great damage to plant growth and development. To survive, plants have evolved strategies to tolerate stress, including developmental, physiological, morphological, ecological, biochemical, and molecular mechanisms [1]. Members of many transcription factor (TF) families, such as AP2/ERF, MYB/MYC, zinc-finger protein, and NAC, play important roles at molecular levels by increasing or decreasing the expression of stress responsive genes [2]. Compared to those TF families, Nuclear Factor Y (NF-Y) is a relatively late reported TF family that participates in abiotic stress response.

NF-Y is a heterotrimeric complex with three distinct subunits, NF-YA, NF-YB, and NF-YC, that binds to the CCAAT element in the promoters of genes [3]. All three subunits contain the conserved DNA binding domains and subunit interaction domains [4]. To form heterotrimeric complexes, NF-YB and NF-YC, who possess H2B and H2A motifs, respectively, form a tight histone dimer in the cytoplasm, 
and the dimer then translocates into the nucleus where it can interact with NF-YA to form the final heterotrimer [5]. Since NF-YA can specifically bind to the CCAAT boxes, the heterotrimer acts as a transcript factor to regulate downstream genes containing CCAAT binding site in promoter [5].

NF-Y is highly conserved in all higher eukaryotes [3]. In yeast and animals, each NF-Y subunit is encoded by a single gene, but in plants, NF-Y subunits are multigene families, which implies that the heterotrimeric NF-Y complexes may act in diverse combinations of subunits for the specific transcriptional regulation [6]. Although no complete NF-Y complex has been reported in plants, the functions of individual subunits are becoming clearer. Many studies have shown that single NF-Ys play important roles in many processes, such as chloroplast biogenesis [7], photomorphogenesis [8], embryogenesis [9], nodule development [10], root growth [11], seed development [12], flowering time [13], and stress response [14-20].

For abiotic stress response, different NF-Y members play positive or negative roles via different mechanisms. Overexpression of AtNF-YA1 or TaNF-YA10-1 significantly increased the plant's sensitivity to salinity [16,21], while overexpression of SiNF-YA5 or OsHAP2E could enhance salt tolerance [14,22]. GmNF-YA3 positively modulated drought tolerance of Arabidopsis through the ABA-dependent pathway, while OsNF-YA7 conferred drought tolerance of rice in an ABA-independent manner [23,24]. Previous studies revealed that many NF-YA genes were involved in the miR169-regulated abiotic stress response [25,26]. Similar to the case of the NF-YA subfamily, AtNF-YB1 and its homologues ZmNF-YB2 enhanced drought tolerance of Arabidopsis and rice, respectively, neither in an ABA-dependent manner nor in an ABA-independent manner [17], but PdNF-YB7 increased drought tolerance through upregulating downstream genes of the ABA-dependent pathway in Arabidopsis [27]. Moreover, the individual $N F-Y B$ gene was reported to be involved in multiple stresses. SiNF- $Y B 8$ can enhance drought and osmotic tolerance in tobacco [28]. Overexpression of PwNF-YB3 can significantly improve tolerance of seedlings under salinity, drought, and osmotic stress [18]. NF- $Y C$ also plays important functions in response to different kinds of stresses. CdtNF-YC1 increased drought and salinity tolerance in rice through regulating genes in both ABA-dependent and ABA-independent pathways [29]. AtHAP5A improved freezing stress resistance in Arabidopsis independent of the CBF pathway [30].

To date, NF-Y transcription factors have been identified in several species, including 33 NF- $Y$ genes in Arabidopsis thaliana [31], 37 NF-Y genes in Triticum aestivum [32], 28 NF-Y genes in Oryza sativa [33], $68 \mathrm{NF}-Y$ genes in Glycine max [34], $33 \mathrm{NF}-\mathrm{Y}$ genes in Brassica napus [35], $36 \mathrm{NF}-Y$ genes in Brachypodium distachyon [36], 34 NF- $Y$ genes in Vitis vinifera L. [37], 19 NF- $Y$ genes in Citrullus lanatus [38], 33 NF-Y genes in Sorghum bicolor (L.) Moench [8], 22 NF-Y genes in Citrus sinensis [39], 33 NF-Y family genes in Phyllostachys edulis [40], 39 NF-Y genes in Setaria italica [28]. However, no information is available on the NF-Y gene family in petunias (Petunia hybrida).

The petunia (Petunia hybrida) is a widely used landscaping plant around the world. Adverse environmental conditions greatly limit its display period and ornamental value. The petunia is also a model plant for studying ornamental plants. Taking advantage of the current draft of the petunia genome, and based on the significance of the NF-Y family in plant development and stress response, we attempted to characterize the petunia $N F-Y$ gene family. In this study, we identified $27 N F-Y$ genes from the petunia genome, analyzed phylogenetic relationships, and conserved protein motifs, exon-intron structures, and micro RNA (miRNA) targeting of the $N F-Y$ genes to further characterize PhNF-Ys. In addition, we analyzed NF-Y gene expression profiles in various tissues and in response to abiotic stresses, including cold, heat, drought, and salt. Our results should provide insights into the function of the NF-Y gene family in petunias.

\section{Results}

\subsection{Identification of the NF-Y Family Members}

A total of 27 NF-Y proteins of Petunia (Table 1) were identified through BLASTP by using full-length amino acid sequences of 36 AtNF-Y proteins. The identified NF-Y proteins were named 
PhNF-YA1-PhNF-YA10, PhNF-YB1-PhNF-YB13, and PhNF-YC1-PhNF-YC4. The characteristics of the PhNF-Y sequences are listed in Table 1. The lengths of gene sequences ranged from $327 \mathrm{bp}$ to $1065 \mathrm{bp}$. The lengths, the molecular weights (MWs), and the isoelectric point (pI) values of these proteins ranged from 108 aa to 327 aa, from $11.92 \mathrm{kDa}$ to $39.76 \mathrm{kDa}$, and from 4.25 to 10.39 , respectively.

Table 1. Basic information of the Nuclear Factor Y (NF-Y) gene family in Petunia.

\begin{tabular}{|c|c|c|c|c|c|c|}
\hline Gene ID & Gene Name & $\begin{array}{c}\text { mRNA } \\
\text { Length (bp) }\end{array}$ & $\begin{array}{l}\text { No. of } \\
\text { Introns }\end{array}$ & $\begin{array}{c}\text { Peptide } \\
\text { Residues (aa) }\end{array}$ & $\begin{array}{c}\text { MW } \\
\text { (kDa) }\end{array}$ & pI \\
\hline Peaxi162Scf00004g02521 & PhNF-YA1 & 933 & 4 & 310 & 33.91 & 7.34 \\
\hline Peaxi162Scf00339g00512 & PhNF-YA2 & 957 & 4 & 312 & 34.05 & 9.85 \\
\hline Peaxi162Scf00038g01819 & PhNF-YA3 & 1065 & 4 & 327 & 36.13 & 9.85 \\
\hline Peaxi162Scf00267g00038 & PhNF-YA4 & 792 & 4 & 286 & 31.70 & 9.37 \\
\hline Peaxi162Scf00953g00217 & PhNF-YA5 & 861 & 5 & 298 & 33.54 & 9.33 \\
\hline Peaxi162Scf00003g04130 & PhNF-YA6 & 585 & 2 & 354 & 39.76 & 6.94 \\
\hline Peaxi162Scf00498g00617 & PhNF-YA7 & 897 & 5 & 318 & 34.72 & 10.04 \\
\hline Peaxi162Scf00809g00019 & PhNF-YA8 & 987 & 4 & 263 & 29.51 & 9.93 \\
\hline Peaxi162Scf00032g00323 & PhNF-YA9 & 939 & 4 & 296 & 33.26 & 7.47 \\
\hline Peaxi162Scf00211g00239 & PhNF-YA10 & 888 & 6 & 194 & 22.19 & 10.39 \\
\hline Peaxi162Scf00195g00082 & PhNF-YB1 & 492 & 3 & 163 & 17.54 & 5.32 \\
\hline Peaxi162Scf00146g01325 & PhNF-YB2 & 420 & 2 & 140 & 15.58 & 5.29 \\
\hline Peaxi162Scf00047g02011 & PhNF-YB3 & 606 & 0 & 201 & 20.52 & 6.68 \\
\hline Peaxi162Scf00037g00085 & PhNF-YB4 & 423 & 0 & 140 & 15.90 & 4.56 \\
\hline Peaxi162Scf00534g00022 & PhNF-YB5 & 420 & 0 & 139 & 15.71 & 4.89 \\
\hline Peaxi162Scf00827g00055 & PhNF-YB6 & 642 & 0 & 213 & 23.69 & 5.10 \\
\hline Peaxi162Scf00525g00067 & PhNF-YB7 & 696 & 0 & 231 & 26.03 & 6.95 \\
\hline Peaxi162Scf00208g00014 & PhNF-YB8 & 534 & 3 & 177 & 19.36 & 5.73 \\
\hline Peaxi162Scf00139g00134 & PhNF-YB9 & 681 & 1 & 226 & 25.43 & 6.79 \\
\hline Peaxi162Scf00005g00493 & PhNF-YB10 & 546 & 4 & 181 & 19.68 & 6.79 \\
\hline Peaxi162Scf00067g00163 & PhNF-YB11 & 501 & 0 & 166 & 18.71 & 8.06 \\
\hline Peaxi162Scf00399g00108 & PhNF-YB12 & 510 & 1 & 169 & 19.32 & 6.94 \\
\hline Peaxi162Scf01006g00035 & PhNF-YB13 & 588 & 0 & 195 & 21.66 & 6.54 \\
\hline Peaxi162Scf00089g00023 & PhNF-YC1 & 732 & 0 & 243 & 26.20 & 5.03 \\
\hline Peaxi162Scf00134g02029 & PhNF-YC2 & 873 & 1 & 291 & 32.20 & 6.08 \\
\hline Peaxi162Scf00128g00124 & PhNF-YC3 & 513 & 0 & 170 & 18.04 & 4.25 \\
\hline Peaxi162Scf00102g01519 & PhNF-YC4 & 327 & 1 & 108 & 11.92 & 10.25 \\
\hline
\end{tabular}

MW: molecular weight; pI: isoelectric point.

\subsection{Multiple Alignment and Conserved Motifs of NF-Y Proteins}

Multiple alignments showed that all PhNF-Y proteins had clear conserved core regions flanked by non-conserved sequences. The core regions of most petunia NF-YA proteins contained two conserved domains, one for the NF-YB/C interaction (20AA) and the other for binding CCAAT domain in the promoter (21AA) (Figure 1a). The two domains were separated by a conserved linker (11AA). However, the PhNF-YA6 and PhNF-YA4 lacked the conserved DNA binding domain of the NF-YA subfamily, which was necessary for the recognition of the CCAAT domain. In addition, a conserved 12 AA sequence with an unknown function was identified in front of the NF-YB/C interaction domain. We also noticed that most amino acid residues required in mammals and yeast $[3,41]$ were remained in most petunia NF-YA proteins. For these required amino acid residues, the arginine (R24) was often replaced by alanine or glycine, and the alanine (A31) was mutative in plant NF-YA proteins [31]. In addition, eight of the petunia NF-YA proteins contained three predicted nuclear localization signals [5,42] (black boxes in Figure 1a). 

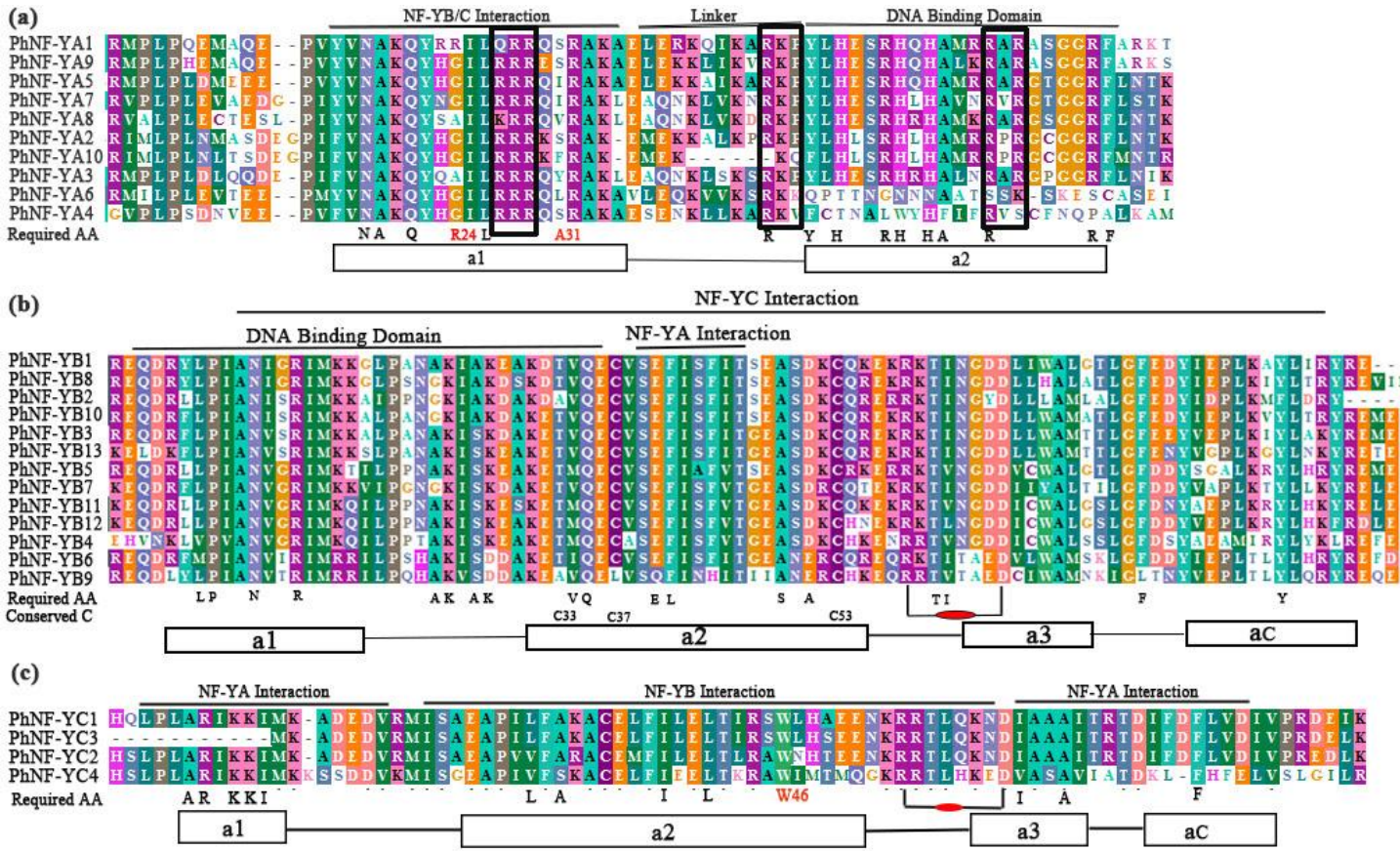

Figure 1. Multiple alignments of conserved domains in three subfamilies of PhNF-Ys. The DNA binding and subunit interaction domain are represented. The alpha-helices (rectangles) and coils (black lines) are marked on the bottom. Required amino acids (Required AA) are given on the bottom of the alignment. (a) Multiple alignments of conserved domains in the PhNF-YA family. The three black boxes in the A group are the residual clusters required for nuclear targeting. (b) Multiple alignments of conserved domains in the PhNF-YB family. Conserved cysteines C33, C37, and C53 of PhNF-YB are marked. (c) Multiple alignments of conserved domains in the PhNF-YC family. The putative arginine $(\mathrm{R})$-aspartate (D) pairs in (b) and (c) are marked.

The conserved region of Petunia NF-YB proteins had structural similarities with H2B histone. This region possessed characteristic domains for DNA-binding and NF-YA/C interaction (Figure 1b). The required amino acid residues were highly conserved in PhNF-YB proteins, particularly the functionally important protein residues. The characteristic intra-chain arginine-aspartate (R58-D65) bidentate pairs, which were necessary in stabilizing the NF-YB/C heterodimer, were absolutely conserved [43]. Notably, similarly with Arabidopsis and soybean, the disulfide bond between C33 and C37 was not presented, which played a crucial role in the translocation of NF-YB/C into nuclei in humans and Aspergillus nidulans [43]. This evidence further confirmed the conserved histone structure and changed the model of nucleus translocation of NF-YB proteins in plants.

The PhNF-YC proteins contained highly conserved NF-YA/B interaction domains and had structural similarities with H2A histone [43]. The required amino acids were conserved with few alterations by similar functional residues [44] (Figure 1c). Similarly with NF-YB subunits, the arginine (R54) and aspartate (D61) pairs were present in all petunia NF-YCs [43]. Another specific feature-tryptophan (W46) at the end of $\alpha 2$, which made the specific interaction of NF-YC and NF-YB, was also absolutely conserved in all PhNF-YCs.

To reveal the evolutionary relationship and potential function of PhNF-Ys, an unrooted neighbor-joining phylogenetic tree was constructed using 63 full-length protein sequences of NF-Ys from Petunia and Arabidopsis (Figure 2). The phylogenetic analysis revealed that the $63 \mathrm{NF}-\mathrm{Y}$ proteins were clustered into three groups: NF-YA (purple), NF-YB (orange), and NF-YC (blue), which were consistent with our subfamily classifications of the PhNF-Ys (Table 1). Based on the genetic relations and the reported functions of AtNF-Ys, the functions of PhNF-Y members could be concluded and further tested. Notably, five pairs of NF-YB orthologues (AtNF-YB7 and PhNF-YB7; AtNF-YB4 and PhNF-YB4; AtNF-YB10 and PhNF-YB10; AtNF-YB6 and PhNF-YB6; AtNF-YB3 and PhNF-YB3) were 
found in the NF-YB group, suggesting a significant possibility of the similar biological functions between the NF-YB orthologues. Moreover, six pairs of paralogues were identified: PhNF-YB1 and PhNF-YB8; PhNF-YB11 and PhNF-YB12; PhNF-YA1 and PhNF-YA9; PhNF-YA5 and PhNF-YA6; PhNF-YA2 and PhNF-YA10; PhNF-YA7 and PhNF-YA8.

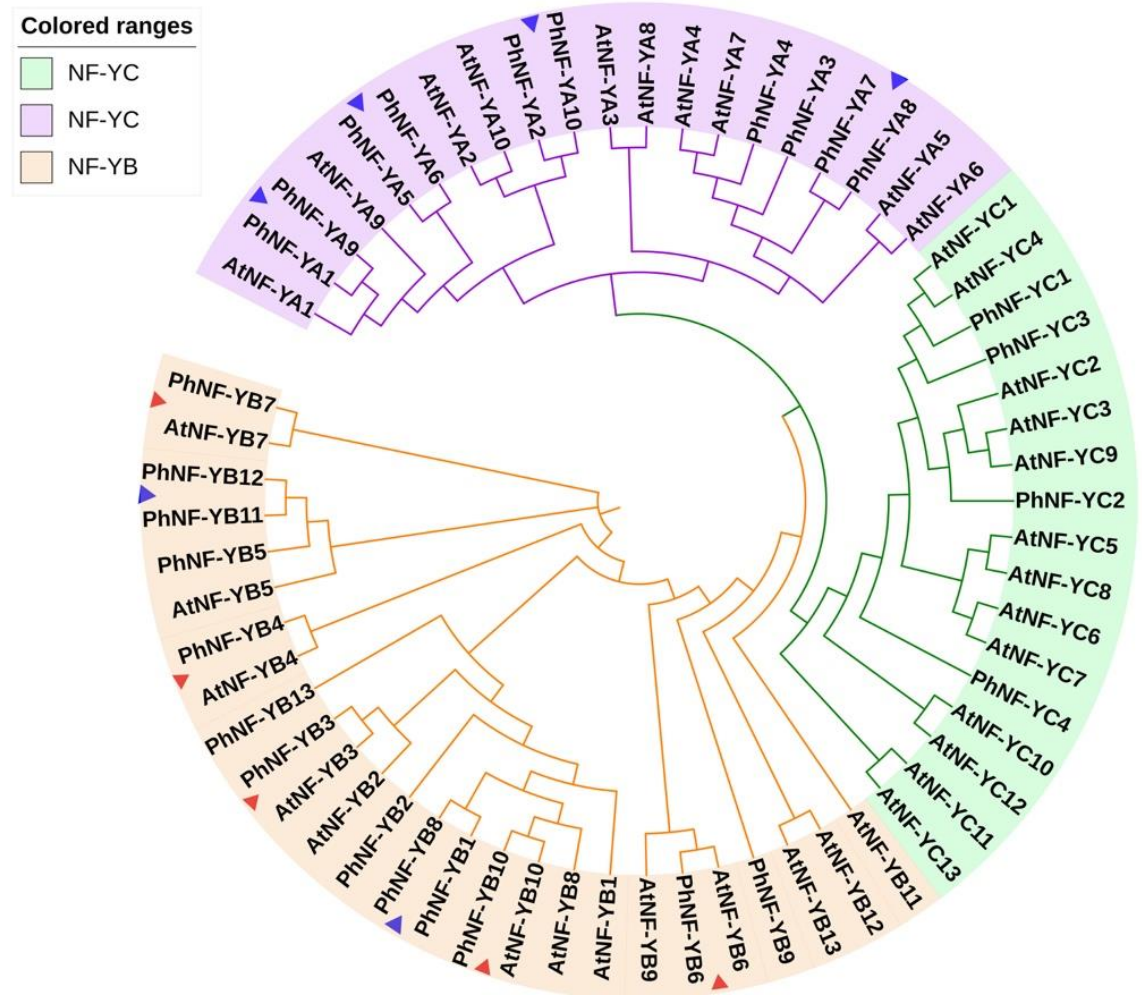

Figure 2. Phylogenetic analysis of NF-Y proteins in Arabidopsis thaliana and Petunia hybrida. Three subfamilies are represented by different colors. $\Delta$ indicates five pairs of orthologues; $\boldsymbol{\Delta}$ indicates six pairs of paralogues.

\subsection{Gene Structures and Conserved Motifs of PhNF-Y Members}

To further understand the evolutionary relationships in the petunia NF-Y family, the exon-intron structures were analyzed using the GSDS website (Figure 3; http://gsds.cbi.pku.edu.cn/index.php). Most of the PhNF-YAs had five or six exons with similar distribution, an exception being PhNF-YA6. Half of the PhNF-YBs had no intron, and the other half were variable, but the members involved in the same clade had similar numbers of exons and introns. For the PhNF-YC subfamily, PhNF-YC1 and PhNF-YC3 had only one exon, and PhNF-YC2 and PhNF-YC4 had two exons. The gene structures of the NF-Y members were positively associated with their phylogenetic relationship and were consistent with the previous reports [8,43].

The putative conserved motifs of 27 PhNF-Ys were identified using Multiple Em for Motif Elicitation (Figure 4; MEME 5.1.0). Ten conserved motifs were recognized in each subfamily, and the lengths of the motifs ranged from 6 to 50 amino acids. For the PhNF-YA subfamily members, Motif 1, 2, and 3 were presented in 8 of the 10 NF-YAs. PhNF-YA4 lacked Motif 1 and 3, and NF-YA8 lacked Motif 3. Furthermore, the members of the same clade contained similar motif numbers and distribution patterns, indicating that they might have similar functions. All PhNF-YB proteins contained Motif 11, 12 , and 13 , and the variation of motifs were consistent with the phylogenetic relationships. In the case of the PhNF-YC subfamily, Motif 21, 22, and 23 were observed in all four members, and Motif 25, 26, 27, and 28 were found in PhNF-YC2 and PhNF-YC4. 


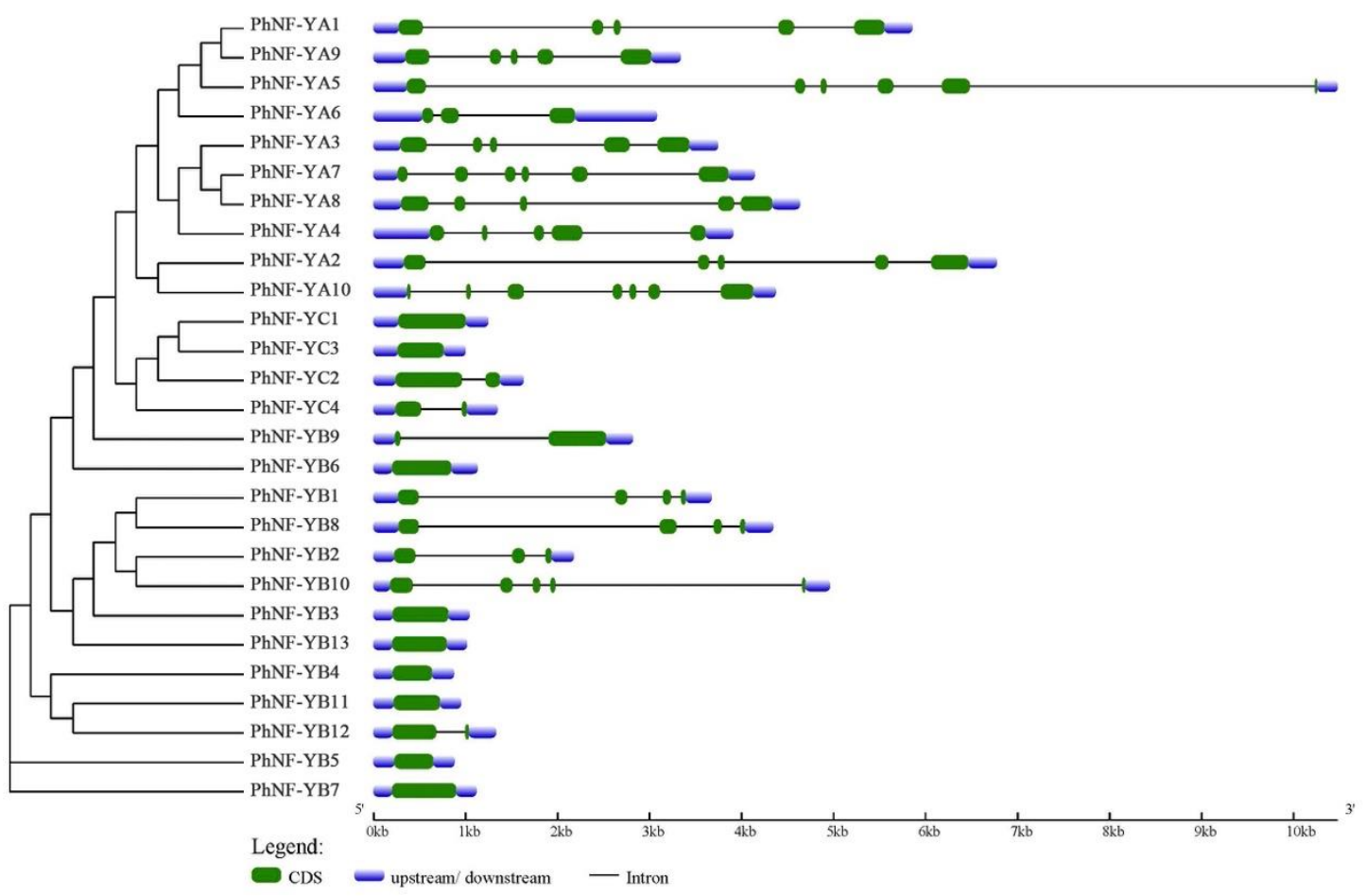

Figure 3. The exon-intron structure of the NF-Y gene family in petunias.

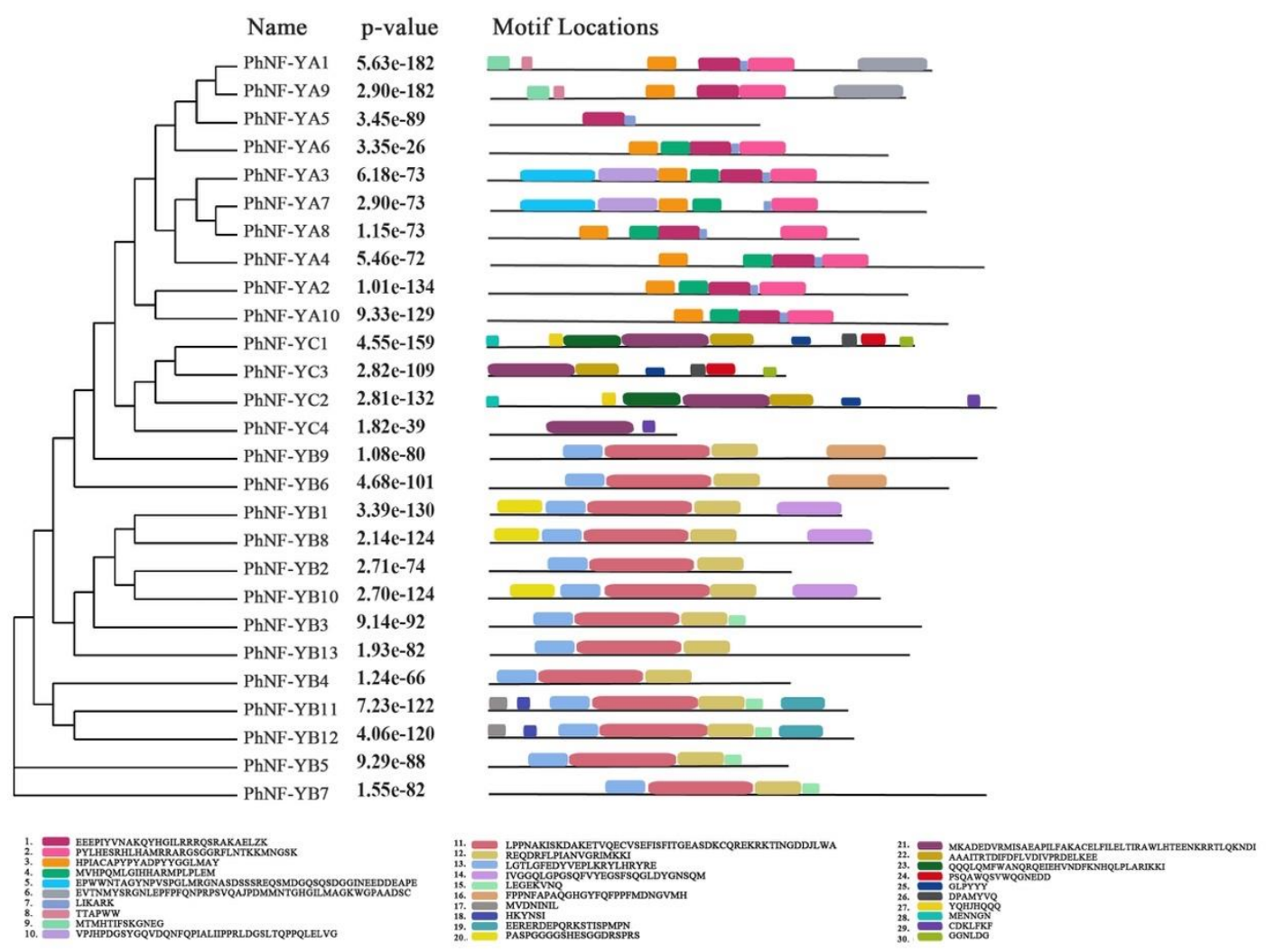

Figure 4. The motif structure of the NF-Y gene family in petunias. Ten conserved motifs of each subfamily were displayed in different colors. The motif sequence information was provided at the bottom. 

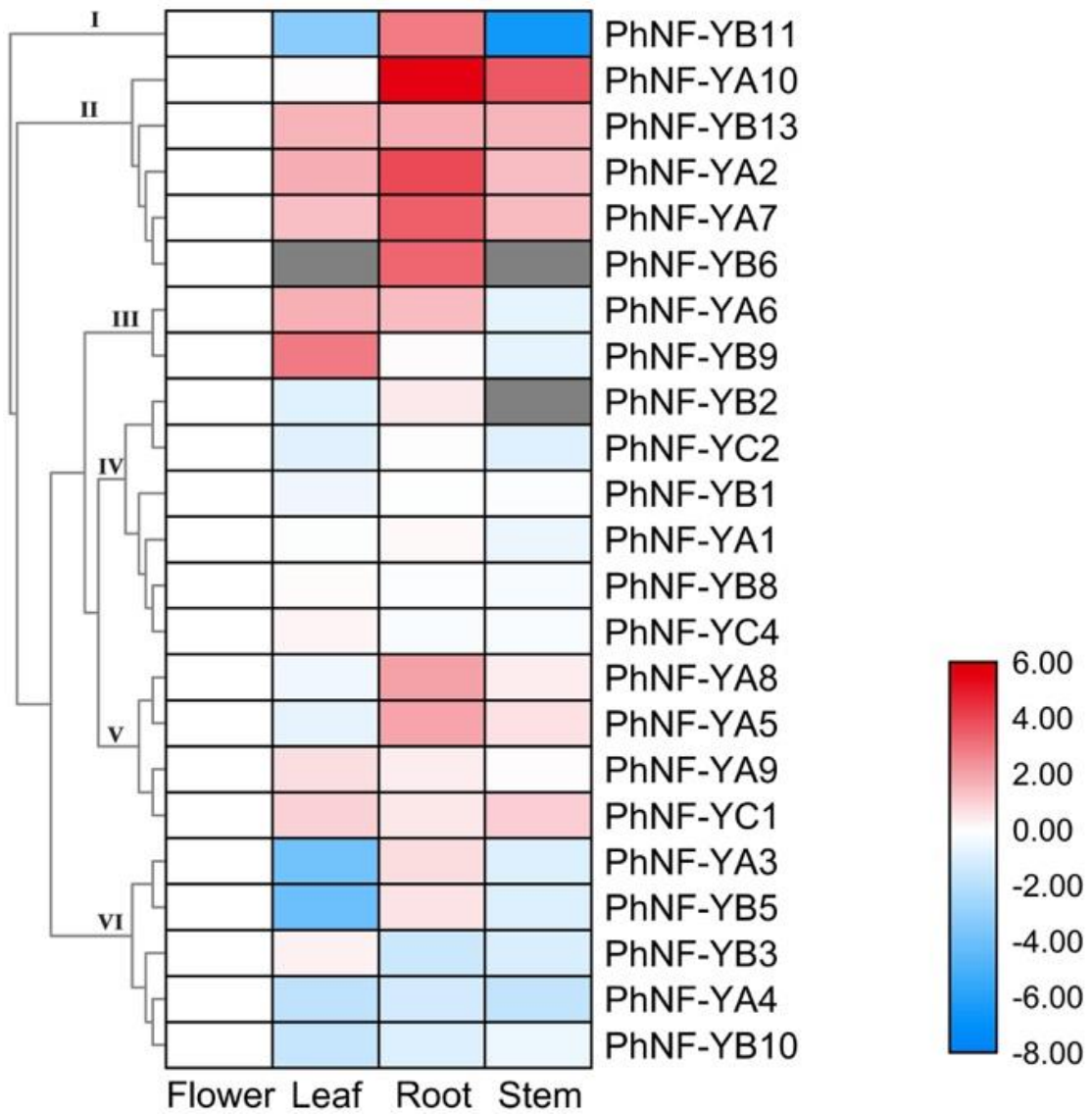

Figure 6. Expression profiles of PhNF-Ys in different tissues. A cluster dendrogram is shown on the left. NF-Ys are divided into six major groups based on their expression patterns. Grey boxes indicate that transcription was not detected at that timepoint. The bar on the lower right corner represents $\log _{2}$-based expression values transformed from fragments per kilobase of exon per million reads mapped (FPKM) values. Blue and red indicate decreased and increased transcript abundance, respectively, compared to controls (flower).

\subsection{Expression Profiles of the PhNF-Ys under Abiotic Stress}

Previous reports have verified that NF-Y members could respond to various abiotic stresses [49]. We performed RNA-seq to identify the expression levels of PhNF-Ys under several stresses (Figure 7). Based on the RNA-seq data, 9 NF- $Y$ genes not detected were omitted from the analysis. The results showed that PhNF-YA6 and -10 and PhNF-YB13 were regulated by drought stress (Figure 7a). PhNF-YA6 and $P h N F-Y A 10$ reached a peak at $6 \mathrm{~h}$ and subsequently decreased to a normal level after $12 \mathrm{~h}$ of treatment, while PhNF-YB13 decreased sharply after $12 \mathrm{~h}$ of treatment. With the salt treatment (Figure $7 \mathrm{~b}$ ), the expression levels of four PhNF-Ys (PhNF-YA5, -6, and -10 and PhNF-YB3) were regulated by salt. PhNF-YA5, -6, and -10 were induced during the early stages, reached the peak at $12 \mathrm{~h}$, and then decreased. The expression level of PhNF-YB3 reached the top at $1 \mathrm{~h}$ and then quickly decreased to a normal level. Under cold stress (Figure 7c), $10 \mathrm{PhNF}$ - Ys were upregulated or downregulated at different timepoints. For NF-YA subfamily members, PhNF-YA1 and PhNF-YA7 were obviously downregulated and $P h N F-Y A 4,-5,-6$, and -10 were markedly upregulated at one or more timepoints, suggesting these genes might have obtained divergent functions under cold stress during evolution. In addition, three $N F-Y B(P h N F-Y B 1,-3$, and 2) members were significantly inhibited after $12 \mathrm{~h}$ of treatment. PhNF-YB13 showed a gradual increase from 3 to $12 \mathrm{~h}$. With hot stress (Figure 7d), four genes were induced, and five genes decreased. PhNF-YA1, -2 , and -10 were increased within $1 \mathrm{~h}$ and PhNF-YC1 exhibited a gradual increase. PhNF-YA4, -5, and -6 and PhNF-YB13 decreased 
immediately in $1 \mathrm{~h}$. The expression of $P h N F-Y A 7$ was the lowest at $6 \mathrm{~h}$. These results suggested that the PhNF-Ys had a faster response to hot stress. Notably, we found that more NF-Y genes participated in temperature stress response, suggesting that these genes might be key candidates for improving tolerance to temperature stress.

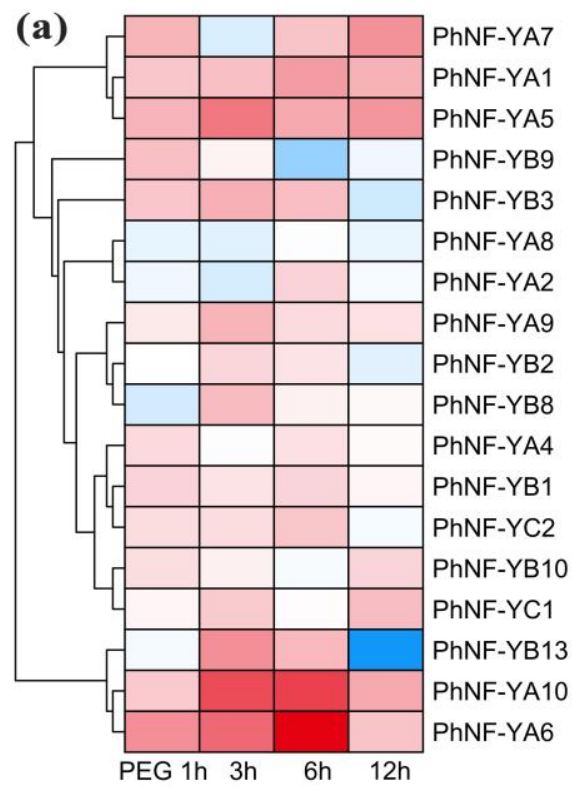

(c)

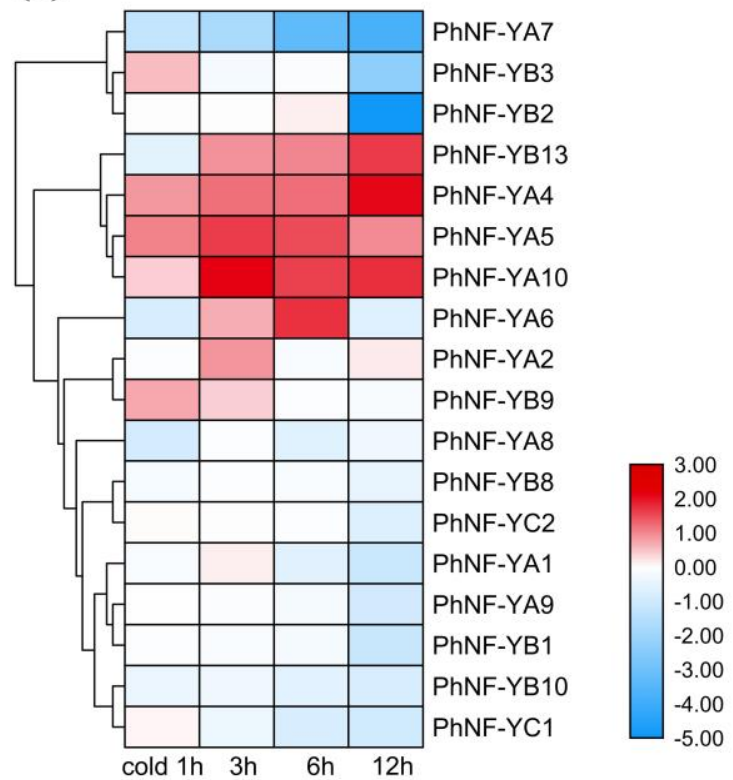

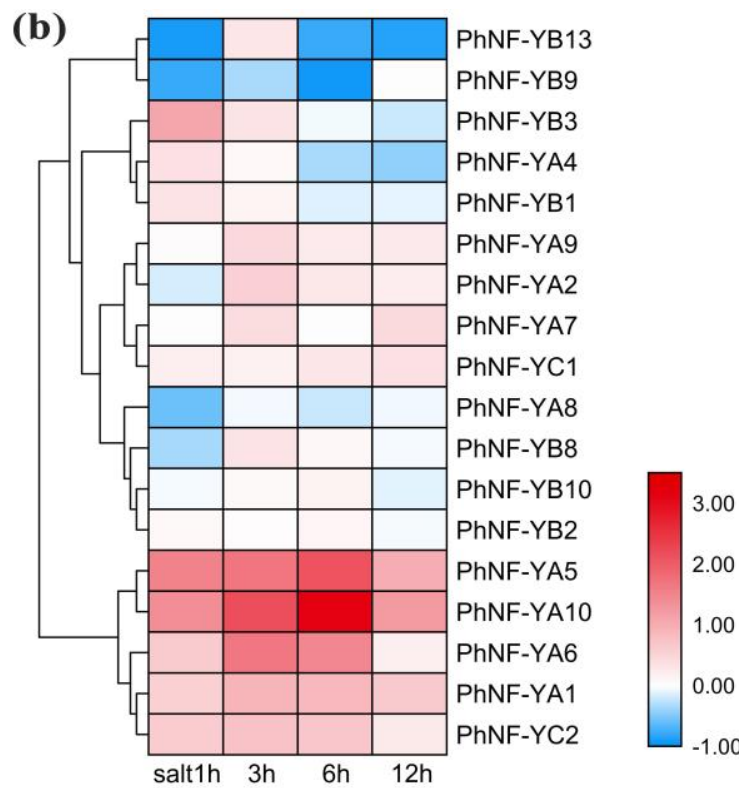

(d)

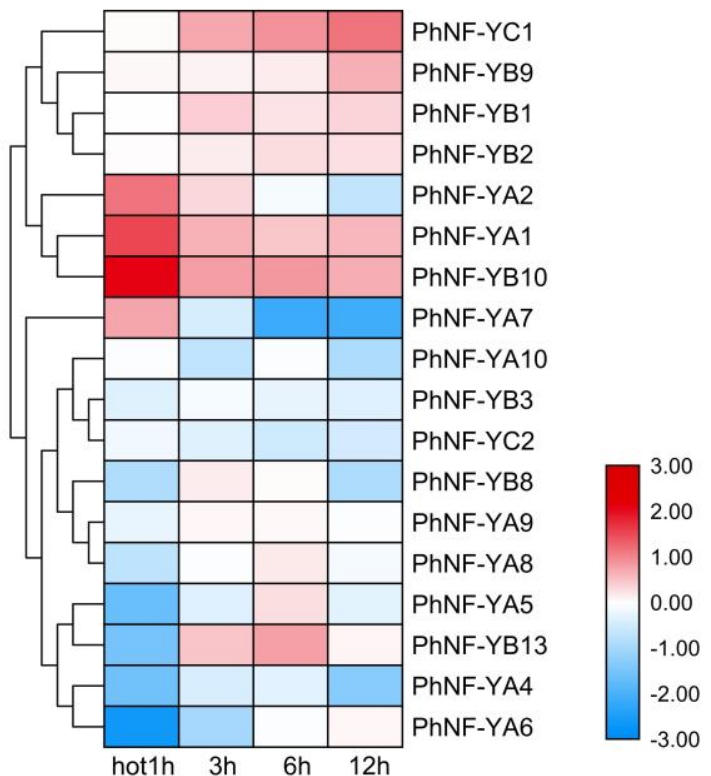

Figure 7. Expression profiles of $P h N F-Y_{s}$ in response to abiotic stress treatments. (a) Expression profiles of $P h N F-Y_{s}$ under drought treatment (20\% PEG). (b) Expression profiles of $P h N F-Y_{s}$ under salt treatment $(500 \mathrm{mM})$. (c) Expression profiles of PhNF-Ys under cold treatment $\left(4^{\circ} \mathrm{C}\right)$. (d) Expression profiles of PhNF-Ys under hot treatment $\left(40^{\circ} \mathrm{C}\right)$. The treatments and timepoint are marked at the bottom of each column. The bars on the right bottom indicate fold-change values ( $\log _{2}$ values) with red representing increased transcript abundance and blue indicating decreased transcript abundance.

\section{Discussion}

Based on the petunia draft genome and the sequences of Arabidopsis NF-Y family members, we initially identified 10 NF-YAs, 13 NF-YBs, 4 NF-YCs, 3 NC2 $\beta$ s, and 1 NC2 $\alpha$, Since NC $2 \alpha / \beta$ could not 
pair with NF-YB/C [50], these four members were removed from further analyses. For the PhNF-YC subfamily, only 4 members were found, less than 10 members of the Arabidopsis NF-YC gene family. The reduced numbers of $P h N F-Y C$ genes could result in a reduction of heterotrimers by two-thirds in theory. Smaller amounts of NF-YC members could also decrease the high redundancy of the NF-Y family in plants.

Multiple alignments showed that most PhNF-Y proteins contained the conserved regions responsible for subunit interaction and DNA binding (Figure 1), which were also found in other plants, mammals, and yeasts [32,38]. Previous studies have shown that the DNA binding domain in the C-terminus of NF-YA could bind to the CCAAT sites [41]. In this study, PhNF-YA4 and PhNF-YA6, which lacked the conserved DNA binding domain, might fail to recognize the CCAAT sites. The functions of these two members were worth further investigation. Additionally, although most required AA were conserved, PhNF-YC4 still exhibited some alterations in the NF-YA interaction domain. In consideration of the absence of homologues of the PhNF-YC4 gene in Arabidopsis, the ability to interact with the NF-YA subunit and the biological function of PhNF-YC4 required further testing.

To explore the functions of these PhNF-Ys, exon-intron structures and evolutionary analysis were performed (Figures 2 and 3). The number and distribution of introns and exons were similar to previous results $[4,8,37]$, suggesting that the functions of $P h N F-Y_{s}$ might be similar to homologues genes in other species. In phylogenetic tree analysis, genes showing a close evolutionary relationship usually have a similar function, so we can predict the functions of PhNF-Ys based on the known functions of AtNF-Ys. For example, AtNF-YB3 was associated with the development of root tissue and flowering time [51], suggesting that its homologues gene, PhNF-YB3, might have similar functions. The higher expression level of PhNF-YB3 in leaf tissue further supported this possibility. AtNF-YA1 and AtNF-YA9 were reported to be critical regulators of embryo development [21,52], suggesting that the PhNF-YA genes clustered in the same clade might have similar functions. PhNF-YC2 and PhNF-YC4 were distant to NF-YCs in Arabidopsis, suggesting that these genes might have a unique role in determining specific traits in petunias. Moreover, the corresponding heterotrimeric complexes might be quite different from that in Arabidopsis.

Previous studies have shown that miRNA169 could direct the cleavage of the mRNA of NF-YA to regulate abiotic stress responses in different plant species $[26,47,53]$. In our study, we identified eight PhNF-YA genes possessing complementary sequences of different miRNA169 members, further supporting the existence of the miRNA169/NF-YA module in petunias. It was noted that some NF-YA genes contained the binding sites of other 13 miRNA family, including miR156, 159, 168,171, 172, $395,482,6164,8016,6149,171(\mathrm{~V})$, and 172(v). The functions of some miRNA were well studied in plants. For example, miR156 was a key component of the aging pathway through directly regulating its targets SQUAMOSA PROMOTER BINDING PROTEIN-LIKE (SPL) at a posttranscriptional level [45]. miRNA164 is involved in plant growth and abiotic stress responses through guiding the cleavage of the mRNAs of NAC genes [54]. The miR172 regulated flowering time and vegetative phase change through clearing the mRNA of AP2 and AP2-like genes [45]. In our study, PhNF-YA1, -2, -5, -7, and -10 showed an obvious stress response. PhNF-YA3 had a higher expression level in flower tissue. The functions of these PhNF-YA genes and the underlying relationships of PhNF-YA and miRNA were worth further investigation. In addition, PhNF-YB2, $-8,-10$, and -12 contained binding sites of miRNA156. In our previous study, $C m N F-Y B 8$ was shown to regulate flowering time via directly binding to the promoter of $c m o-M I R 156$ [55]. In this study, the expression level of PhNF-YB8 was relatively constant. The function of PhNF-YB8 and the relationship of PhNF-YB8 and miR156 in petunias might differ from the situation in chrysanthemum. For the NF-YC subfamily, we first revealed that $P h N F-Y C 2$ contained target sites of miRNA164 and miRNA171(v), and PhNF-YC3 contained target sites of miRNA394. Both miR164 and miR171 were involved in stress response [45], and miR394 played roles in flower development [45]. The deeper relationships of NF-YC and miRNAs need to be explored.

Many NF- $Y$ genes have been reported to participate in drought and salt stress responses. In previous studies, NF-Y genes regulated drought tolerance via different mechanisms, including the 
ABA-dependent pathway, the ABA-independent pathway, and even novel mechanisms. In our study, only PhNF-YA6 and -10 and PhNF-YB13 responded to drought. In previous studies, AtNF-YA6 involved ABA signaling [34], and GmNF-YA21, the homologues of AtNF-YA10, played roles in drought response [34]. Our results indicated that PhNF-YA6 and PhNF-YA10 were highly expressed in root tissue, which had a close relationship with stress tolerance, supporting the idea that PhNF-YA6 and PhNF-YA10 might be associated with drought response. PhNF-YB13 showed distant relationships with other NF-YB members, and had a high expression in leaves, roots, and stems, so its function requires further study. Salt stress showed a similar pattern of drought stress, and PhNF-YA5, -6, and -10 were quickly induced and were highly expressed in roots. In Arabidopsis, the induction of AtNF-YA5 under drought occurred at both the transcriptional and posttranscriptional levels [15]. The tissue-specificity of PhNF-YA5 expression indicated that it had higher expression in roots and stems. In our study, PhNF-YA5 was weakly induced after $3 \mathrm{~h}$ of drought stress. We speculated that PhNF-YA5 might regulate salt tolerances through regulating root or stem development. It has been well known that the mechanisms of drought response and salt response overlap to some degree. It is easier to understand that PhNF-YA5, -6, and -10 responded to both drought and salt. PhNF-YB3 was quickly induced by salt. AtNF-YB3, the homologues of $P h N F-Y B 3$, was identified to regulate flowering time [34]. In our study, PhNF-YB3 showed higher expression in leaf and flower tissue. We concluded that PhNF-YB3 should play roles in flowering time regulation and salt response, which requires further evidence.

There is little evidence that NF-Y genes are involved in cold and hot responses [30]. In our study, $10 \mathrm{PhNF}-Y$ genes were obviously induced or suppressed by cold responses, and 9 PhNF-Y genes quickly responded to hot responses. Among these genes, seven (PhNF-YA1, -4, -5, -6, -7, and -10 and PhNF-YB13) were involved in both cold and hot responses. The expression of PhNF-YA4, -5 , and -6 increased under cold responses and decreased under hot responses. The performances of PhNF-YA7 and -10 and PhNF-YB13 were similar under hot and cold responses. Moreover, except for PhNF-YA4, six other genes showed high expression in roots, indicating the underlying mechanisms that might be overlapped to a certain extent. Notably, we found that PhNF-YA6 and PhNF-YA10 responded to all stresses, including drought, salt, and cold and hot stress, indicating their multifunctional roles under different abiotic stresses. In our studies, more PhNF-Y genes responded to hot and cold stresses than to drought and salt. We concluded that PhNF-Y genes might play unknown, important roles in temperature stress. However, we could not rule out the possibility that different treatment concentrations and times result in dramatic expression changes under drought or salt treatment. In conclusion, the results of the stress response experiments, together with the tissue-specific expression, suggested that many PhNF-Y genes might respond to stresses through regulating root or leaf development. These PhNF-Y genes deserve further research and might be utilized for improving the abiotic stresses tolerance of petunias.

\section{Materials and Methods}

\subsection{Identification, Alignments, and Phylogenetic Analysis of NF-Y Members}

The sequences of 36 Arabidopsis NF-Y proteins were obtained from the Arabidopsis Information Resource (TAIR, https://www.arabidopsis.org/). The full length of all Arabidopsis NF-Y proteins were used as queries to blast petunia NF-Y protein sequences from Sol Genomics Network (SGN, https://www. solgenomics.net/). Alignments of full-length amino acid sequences of identified PhNF-Ys and AtNF-Ys were performed using ClustalX (http://www.clustal.org/) and BioEdit. Based on the sequence alignments generated by ClustalX, all potentially redundant NF-Y sequences were discarded. Phylogenetic trees were constructed using MEGA6 [56] and the neighbor-joining method with 1000 bootstrap replicates. The dendrograms were drawn by the online tool of iTOL (https://itol.embl.de/).

Molecular weight (MW) and isoelectric point (pI) of the deduced amino acid sequences were predicted with the Sequences Manipulation Suite (https://www.genscript.com/sms2/index.html). 


\subsection{Conserved Motifs and Gene Structure Analyses}

PhNF-Y conserved motifs were identified using the Multiple Em for Motif Elicitation (MEME, http://www.meme.sdsc.edu/meme/meme.html). The parameter settings were as follows: the maximum number of motifs was set to 10 , the width range was 6-55, and other factors were at default selections [8].

Information about Genomic DNA Sequences and Coding Sequences (CDS) were obtained from the SGN database. The exon-intron structures of the PhNF-YS were constructed using Gene Structure Display Server 2.0 (http://gsds.cbi.pku.edu.cn/).

\section{3. miRNA Target Site Prediction}

Genomic DNA sequences of 27 AtNF-Ys were used to predict the possible targets of all mature miRNA members using the online tool PsRNA server (http://plantgrn.noble.org/psRNATarget/). Parameters are set as follows: The maximum expectation value is 3.5 , the length for complementarity scoring (hsp size) is $21 \mathrm{bp}$, target accessibility (UPE) is 25 , flanking sequence length is $17 \mathrm{bp}$ in upstream and $13 \mathrm{bp}$ in downstream, and the translational inhibition range is 9-11NT.

\subsection{Plant Material, Tissue, and Stress Treatment}

Petunia "Ultra" seeds were grown in $7 \mathrm{~cm}$ diameter pots containing sterile nutrient soil and cultured in a room at $22 \pm 3^{\circ} \mathrm{C}$ under an LD cycle ( $14 \mathrm{~h}$ light $/ 10 \mathrm{~h}$ dark). The 10 -leaf stage seedlings were exposed to varieties of abiotic stresses in chambers, including cold stress $\left(4^{\circ} \mathrm{C}\right)$, hot stress $\left(40^{\circ} \mathrm{C}\right)$, drought stress (20\% polyethylene glycol-6000 (PEG-6000)), and salt stress ( $500 \mathrm{mM} \mathrm{NaCl})$. For the temperature treatment, seedlings were exposed at either $4{ }^{\circ} \mathrm{C}$ or $40{ }^{\circ} \mathrm{C}$ in a chamber with an LD cycle (14 h light/10 $\mathrm{h}$ dark), after which the second fully expanding leaves from the top were sampled. For the $\mathrm{NaCl}$ and PEG 6000 assays, seedlings were transferred to $22^{\circ} \mathrm{C}$ water containing the stress agent in chambers at $22{ }^{\circ} \mathrm{C}$ under an LD cycle ( $14 \mathrm{~h} \mathrm{light} / 10 \mathrm{~h}$ dark), and the second fully expanding leaves from the top were sampled [57]. Samples were collected at $0 \mathrm{~h}, 1 \mathrm{~h}, 3 \mathrm{~h}, 6 \mathrm{~h}$, and $12 \mathrm{~h}$, immediately frozen in liquid nitrogen, and stored at $-80{ }^{\circ} \mathrm{C}$. Each treatment was replicated three times.

In the tissue expression pattern experiment, samples of roots, stems, and leaves were collected from seedlings without bloom. The first flowers of three individual plants were collected as flower samples. The samples were frozen in liquid nitrogen and stored at $-80^{\circ} \mathrm{C}$.

\subsection{Transcriptome Data Analysis}

Total RNA samples were extracted from the above samples using TRIZOL (Invitrogn, Carlsbad, CA, USA) following the manufacturer's protocol [58]. The integrity of the RNA samples was confirmed by electrophoresis on $1 \%$ agarose gels, and the amount and quality of RNA were detected by NanoDrop 2000 Spectrophotometer (Thermo Scientific, Waltham, MA, USA) [37]. RNA-Seq libraries were prepared and sequenced using a HiSeq 2000 (Illumina) at the Shanghai Origingene Biotechnology Co. Ltd. (http://www.origin-gene.com/). RNA-seq data were processed and assembled as previously described [55]. After removing low-quality reads, adapters, and barcode sequences, high-quality clean reads were assembled de novo into contigs. The resulting contigs were blasted against Petunia axillaris draft genome sequence databases (https://www.solgenomics.net/organism/ Petunia_axillaris/genome) with a cutoff $E$ value of $1 \times 10^{-5}$. The Reads Per Kilobase of exon model per Million mapped reads $(\mathrm{FPKM})$ values of all genes were determined with a treatment of $\log _{2}(\mathrm{X})$, and subsequently used for generating heatmaps. Finally, a series of heat maps was generated using TBtools [59].

Supplementary Materials: The following are available online at http://www.mdpi.com/2223-7747/9/3/336/s1. Table S1: Identification of mature miRNAs and targeted NF-Y genes in Petunia. Table S2: Spectrophotometric analyses of RNA samples from plants under different stress treatments. Table S3: Spectrophotometric analyses of RNA samples from different tissues. Figure S1: Electropherograms of RNA samples.

Author Contributions: Conceptualization: Q.W. and S.W.; methodology: S.W. and C.L.; software: C.L.; data curation: Q.W. and S.W.; writing—Original draft preparation: Q.W. and S.W.; writing—Review and editing: Y.Y. 
and G.C.; project administration: G.C.; funding acquisition: Q.W. and G.C. All authors have read and agreed to the published version of the manuscript.

Funding: This research was funded by the National Natural Science Foundation of China, grant number 31701953, and the Natural Science Foundation of Guangdong Province of China, grant number 2019A1515012168.

Conflicts of Interest: The authors declare that there is no conflict of interest.

\section{References}

1. Salehi-Lisar, S.Y.; Bakhshayeshan-Agdam, H. Drought Stress in Plants: Causes, Consequences, and Tolerance; Springer: Cham, Germany, 2016.

2. Yamaguchi-Shinozaki, K.; Shinozaki, K. Organization of cis-acting regulatory elements in osmotic- and cold-stress-responsive promoters. Trends Plant. Sci. 2005, 10, 88-94. [CrossRef] [PubMed]

3. Maity, S.N.; De Crombrugghe, B. Role of the CCAAT-binding protein CBF/NF-Y in transcription. Trends Biochem. Sci. 1998, 23, 174-178. [CrossRef]

4. Li, M.; Li, G.; Liu, W.; Dong, X.; Zhang, A. Genome-wide analysis of the NF-Y gene family in peach (Prunus persica L.). BMC Genom. 2019, 20,1-15. [CrossRef] [PubMed]

5. Kahle, J.; Baake, M.; Doenecke, D.; Albig, W. Subunits of the Heterotrimeric Transcription Factor NF-Y Are Imported into the Nucleus by Distinct Pathways Involving Importin and Importin 13. Mol. Cell. Biol. 2005, 25, 5339-5354. [CrossRef] [PubMed]

6. Gusmaroli, G.; Tonelli, C.; Mantovani, R. Regulation of novel members of the Arabidopsis thaliana CCAAT-binding nuclear factor Y subunits. Gene 2002, 283, 41-48. [CrossRef]

7. Miyoshi, K.; Ito, Y.; Serizawa, A.; Kurata, N. OsHAP3 genes regulate chloroplast biogenesis in rice. Plant J. 2003, 36, 532-540. [CrossRef]

8. Malviya, N.; Jaiswal, P.; Yadav, D. Genome- wide characterization of Nuclear Factor Y (NF-Y) gene family of sorghum [Sorghum bicolor (L.) Moench]: A bioinformatics approach. Physiol. Mol. Biol. Plants 2016, 22, 33-49. [CrossRef]

9. West, M.A.L.; Yee, K.M.; Danao, J.; Zimmerman, J.L.; Fischer, R.L.; Goldberg, R.B.; Harada, J.J. LEAFY COTYLEDON1 Is an Essential Regulator of Late Embryogenesis and Cotyledon Identity in Arabidopsis. Plant Cell 1994, 6, 1731-1745. [CrossRef]

10. Rey, T.; Laporte, P.; Bonhomme, M.; Jardinaud, M.F.; Huguet, S.; Balzergue, S.; Dumas, B.; Niebel, A.; Jacquet, C. MtNF-YA1, a central transcriptional regulator of symbiotic nodule development, is also a determinant of medicago truncatula susceptibility toward a root pathogen. Front. Plant Sci. 2016, 7, 1-14. [CrossRef]

11. Battaglia, M.; Rípodas, C.; Clúa, J.; Baudin, M.; Aguilar, O.M.; Niebel, A.; Zanetti, M.E.; Blanco, F.A. A Nuclear Factor Y Interacting Protein of the GRAS Family Is Required for Nodule Organogenesis, Infection Thread Progression, and Lateral Root Growth. Plant Physiol. 2014, 164, 1430-1442. [CrossRef]

12. Parcy, F.; Valon, C.; Kohara, A.; Miséra, S.; Giraudat, J. The ABSCISIC ACID-INSENSITIVE3, FUSCA3, and LEAFY COTYLEDON1 loci act in concert to control multiple aspects of Arabidopsis seed development. Plant Cell 1997, 9, 1265-1277.

13. Hou, X.; Zhou, J.; Liu, C.; Liu, L.; Shen, L.; Yu, H. Nuclear factor Y-mediated H3K27me3 demethylation of the SOC1 locus orchestrates flowering responses of Arabidopsis. Nat. Commun. 2014, 5, 1-14. [CrossRef]

14. Alam, M.M.; Tanaka, T.; Nakamura, H.; Ichikawa, H.; Kobayashi, K.; Yaeno, T.; Yamaoka, N.; Shimomoto, K.; Takayama, K.; Nishina, H.; et al. Overexpression of a rice heme activator protein gene (OsHAP2E) confers resistance to pathogens, salinity and drought, and increases photosynthesis and tiller number. Plant Biotechnol. J. 2015, 13, 85-96. [CrossRef]

15. Li, W.X.; Oono, Y.; Zhu, J.; He, X.J.; Wu, J.M.; Iida, K.; Lu, X.Y.; Cui, X.; Jin, H.; Zhu, J.K. The Arabidopsis NFYA5 transcription factor is regulated transcriptionally and posttranscriptionally to promote drought resistance. Plant Cell 2008, 20, 2238-2251. [CrossRef]

16. Ma, X.; Zhu, X.; Li, C.; Song, Y.; Zhang, W.; Xia, G.; Wang, M. Overexpression of wheat NF-YA10 gene regulates the salinity stress response in Arabidopsis thaliana. Plant Physiol. Biochem. 2015, 86, $34-43$. [CrossRef] [PubMed] 
17. Nelson, D.E.; Repetti, P.P.; Adams, T.R.; Creelman, R.A.; Wu, J.; Warner, D.C.; Anstrom, D.C.; Bensen, R.J.; Castiglioni, P.P.; Donnarummo, M.G.; et al. Plant nuclear factor Y (NF-Y) B subunits confer drought tolerance and lead to improved corn yields on water-limited acres. Proc. Natl. Acad. Sci. USA 2007, 104, 16450-16455. [CrossRef] [PubMed]

18. Baomei, W.; Zhaoxia, L.; Qijun, R.; Peng, L.; Zhenghua, P.; Juren, Z. ZmNF-YB16 Overexpression Improves Drought Resistance and Yield by Enhancing Photosynthesis and the Antioxidant Capacity of Maize Plants. Front. Plant Sci. 2018, 9, 709.

19. Shi, H.; Ye, T.; Zhong, B.; Liu, X.; Chan, Z. AtHAP5A modulates freezing stress resistance in Arabidopsis through binding to CCAAT motif of AtXTH21. New Phytol. 2014, 203, 554-567. [CrossRef]

20. Liu, X.; Hu, P.; Huang, M.; Tang, Y.; Li, Y.; Li, L.; Hou, X. The NF-YC-RGL2 module integrates GA and ABA signalling to regulate seed germination in Arabidopsis. Nat. Commun. 2016, 7, 1-14. [CrossRef]

21. Li, Y.J.; Fang, Y.; Fu, Y.R.; Huang, J.G.; Wu, C.A.; Zheng, C.C. NFYA1 Is Involved in Regulation of Postgermination Growth Arrest Under Salt Stress in Arabidopsis. PLoS ONE 2013, 8, e61289. [CrossRef]

22. Huang, S.; Hu, L.Q.; Xu, D.B.; Li, W.W.; Xu, Z.S.; Li, L.C.; Zhou, Y.B.; Diao, X.M.; Jia, G.Q.; Ma, Y.Z. Transcription Factor Si NF-YA5 from Foxtail Millet (Setaria italica) Conferred Tolerance to High-salt Stress through ABA-independent Pathway in Transgenic Arabidopsis. Acta Agron. Sin. 2016, 42, 1787-1797. [CrossRef]

23. Ni, Z.; Hu, Z.; Jiang, Q.; Zhang, H. GmNFYA3, a target gene of miR169, is a positive regulator of plant tolerance to drought stress. Plant Mol. Biol. 2013, 82, 113-129. [CrossRef] [PubMed]

24. Lee, D.K.; Kim, H.I.; Jang, G.; Chung, P.J.; Jeong, J.S.; Kim, Y.S.; Bang, S.W.; Jung, H.; Choi, Y.D.; Kim, J.K. The NF-YA transcription factor OsNF-YA7 confers drought stress tolerance of rice in an abscisic acid independent manner. Plant Sci. 2015, 241, 199-210. [CrossRef] [PubMed]

25. Luan, M.; Xu, M.; Lu, Y.; Zhang, Q.; Zhang, L.; Zhang, C.; Fan, Y.; Lang, Z.; Wang, L. Family-Wide Survey of miR169s and NF-YAs and Their Expression Profiles Response to Abiotic Stress in Maize Roots. PLoS ONE 2014, 9, e91369. [CrossRef]

26. Luan, M.; Xu, M.; Lu, Y.; Zhang, L.; Fan, Y.; Wang, L. Expression of zma-miR169 miRNAs and their target ZmNF-YA genes in response to abiotic stress in maize leaves. Gene 2015, 555, 178-185. [CrossRef] [PubMed]

27. Han, X.; Tang, S.; An, Y.; Zheng, D.C.; Xia, X.L.; Yin, W.L. Overexpression of the poplar NF-YB7 transcription factor confers drought tolerance and improves water-use efficiency in Arabidopsis. J. Exp. Bot. 2013, 64, 4589-4601. [CrossRef]

28. Feng, Z.J.; He, G.H.; Zheng, W.J.; Lu, P.P.; Chen, M.; Gong, Y.M.; Ma, Y.Z.; Xu, Z.S. Foxtail millet NF-Y families: Genome-wide survey and evolution analyses identified two functional genes important in abiotic stresses. Front. Plant Sci. 2015, 6, 1-19. [CrossRef]

29. Chen, M.; Zhao, Y.; Zhuo, C.; Lu, S.; Guo, Z. Overexpression of a NF-YC transcription factor from bermudagrass confers tolerance to drought and salinity in transgenic rice. Plant Biotechnol. J. 2014, 13, 482-491. [CrossRef]

30. Shi, H.; Chan, Z. AtHAP5A modulates freezing stress resistance in arabidopsis independent of the CBF pathway. Plant Signal. Behav. 2014, 203, 554-567.

31. Siefers, N.; Dang, K.K.; Kumimoto, R.W.; Bynum IV, W.E.; Tayrose, G.; Holt, B.F. Tissue-specific expression patterns of Arabidopsis NF-Y transcription factors suggest potential for extensive combinatorial complexity. Plant Physiol. 2009, 149, 625-641. [CrossRef]

32. Stephenson, T.J.; McIntyre, C.L.; Collet, C.; Xue, G.-P. Genome-wide identification and expression analysis of the NF-Y family of transcription factors in Triticum aestivum. Plant Mol. Biol. 2007, 65, 77-92. [CrossRef] [PubMed]

33. Thirumurugan, T.; Ito, Y.; Kubo, T.; Serizawa, A.; Kurata, N. Identification, characterization and interaction of HAP family genes in rice. Mol. Genet. Genom. 2008, 279, 279-289. [CrossRef] [PubMed]

34. Quach, T.N.; Nguyen, H.T.M.; Valliyodan, B.; Joshi, T.; Xu, D.; Nguyen, H.T. Genome-wide expression analysis of soybean NF-Y genes reveals potential function in development and drought response. Mol. Genet. Genom. 2015, 290, 1095-1115. [CrossRef] [PubMed]

35. Liang, M.; Yin, X.; Lin, Z.; Zheng, Q.; Liu, G.; Zhao, G. Identification and characterization of NF-Y transcription factor families in Canola (Brassica napus L.). Planta 2014, 239, 107-126. [CrossRef] 
36. Cao, S.; Kumimoto, R.W.; Siriwardana, C.L.; Risinger, J.R.; Holt, B.F. Identification and characterization of NF-Y transcription factor families in the monocot model plant Brachypodium distachyon. PLoS ONE 2011, 6, e21805. [CrossRef]

37. Ren, C.; Zhang, Z.; Wang, Y.; Li, S.; Liang, Z. Genome-wide identification and characterization of the NF-Y gene family in grape (vitis vinifera L.). BMC Genom. 2016, 17, 1-16. [CrossRef]

38. Yang, J.; Zhu, J.; Yang, Y. Genome-Wide Identification and Expression Analysis of NF-Y Transcription Factor Families in Watermelon (Citrullus lanatus). J. Plant Growth Regul. 2017, 36, 590-607. [CrossRef]

39. Pereira, S.L.S.; Martins, C.P.S.; Sousa, A.O.; Camillo, L.R.; Araújo, C.P.; Alcantara, G.M.; Camargo, D.S.; Cidade, L.C.; De Almeida, A.A.F.; Costa, M.G.C. Genome-wide characterization and expression analysis of citrus NUCLEAR FACTOR-Y (NF-Y) transcription factors identified a novel NF-YA gene involved in drought-stress response and tolerance. PLoS ONE 2018, 13, 1-22. [CrossRef] [PubMed]

40. Wang, S.; Ying, F.U.; Zhou, M. Genome-wide Identification and Expression Analysis of the NF-Y Family Genes in Phyllostachys edulis. J. Nucl. Agric. Sci. 2018, 32, 1513-1527.

41. Xing, Y.; Fikes, J.D.; Guarente, L. Mutations in yeast HAP2/HAP3 define a hybrid CCAAT box binding domain. EMBO J. 1993, 12, 4647-4655. [CrossRef] [PubMed]

42. Thön, M.; Abdallah, Q.A.; Hortschansky, P.; Scharf, D.H.; Eisendle, M.; Haas, H.; Brakhage, A.A. The CCAAT-binding complex coordinates the oxidative stress response in eukaryotes. Nucleic Acids Res. 2009, 38, 1098-1113. [CrossRef] [PubMed]

43. Hackenberg, D.; Wu, Y.; Voigt, A.; Adams, R.; Schramm, P.; Grimm, B. Studies on differential nuclear translocation mechanism and assembly of the three subunits of the arabidopsis thaliana transcription factor NF-Y. Mol. Plant 2012, 5, 876-888. [CrossRef] [PubMed]

44. Sinha, S.; Kim, I.S.; Sohn, K.Y.; de Crombrugghe, B.; Maity, S.N. Three classes of mutations in the A subunit of the CCAAT-binding factor CBF delineate functional domains involved in the three-step assembly of the CBF-DNA complex. Mol. Cell. Biol. 1996, 16, 328-337. [CrossRef] [PubMed]

45. Chen, X. microRNA biogenesis and function in plants. FEBS Lett. 2005, 579, 5923-5931. [CrossRef]

46. Bombarely, A.; Moser, M.; Amrad, A.; Bao, M.; Bapaume, L.; Barry, C.S.; Bliek, M.; Boersma, M.R.; Borghi, L.; Bruggmann, R.; et al. Insight into the evolution of the Solanaceae from the parental genomes of Petunia hybrida. Nat. Plants 2016, 2,1-9. [CrossRef]

47. Xu, M.; Zhu, J.; Zhang, M.; Wang, L. Advances on plant miR169/NF-YA regulation modules. Yi Chuan Hereditas 2016, 38, 700-706.

48. Zhao, B.; Ge, L.; Liang, R.; Wei, L.; Jin, Y. Members of miR-169 family are induced by high salinity and transiently inhibit the NF-YA transcription factor. BMC Mol. Biol. 2009, 10, 29. [CrossRef]

49. Swain, S.; Myers, Z.A.; Siriwardana, C.L.; Holt, B.F. The multifaceted roles of NUCLEAR FACTOR-Y in Arabidopsis thaliana development and stress responses. Biochim. Biophys. Acta Gene Regul. Mech. 2017, 1860, 636-644. [CrossRef]

50. Zemzoumi, K.; Frontini, M.; Bellorini, M.; Mantovani, R.; Milano, Á. NF-Y Histone Fold a 1 Helices Help Impart CCAAT Specificity. J. Mol. Biol. 1999, 286, 327-337. [CrossRef]

51. Zhang, T.; Zhang, D.; Liu, Y.; Luo, C.; Zhou, Y.; Zhang, L. Overexpression of a NF-YB3 transcription factor from Picea wilsonii confers tolerance to salinity and drought stress in transformed Arabidopsis thaliana. Plant Physiol. Biochem. 2015, 94, 153-164. [CrossRef]

52. Mu, J.; Tan, H.; Hong, S.; Liang, Y.; Zuo, J. Arabidopsis transcription factor genes NF-YA1, 5, 6, and 9 play redundant roles in male gametogenesis, embryogenesis, and seed development. Mol. Plant 2013, 6, 188-201. [CrossRef] [PubMed]

53. Zhang, X.; Zou, Z.; Gong, P.; Zhang, J.; Ziaf, K.; Li, H.; Xiao, F.; Ye, Z. Over-expression of microRNA169 confers enhanced drought tolerance to tomato. Biotechnol. Lett. 2011, 33, 403-409. [CrossRef] [PubMed]

54. Zhuo, X.; Zheng, T.; Zhang, Z.; Zhang, Y.; Jiang, L.; Ahmad, S.; Sun, L.; Wang, J.; Cheng, T.; Zhang, Q. Genome-wide analysis of the NAC transcription factor gene family reveals differential expression patterns and cold-stress responses in the woody plant prunus mume. Genes 2018, 9, 494. [CrossRef] [PubMed]

55. Wei, Q.; Ma, C.; Xu, Y.; Wang, T.; Chen, Y.; Lü, J.; Zhang, L.; Jiang, C.Z.; Hong, B.; Gao, J. Control of chrysanthemum flowering through integration with an aging pathway. Nat. Commun. 2017, 8, 1-11. [CrossRef]

56. Tamura, K.; Stecher, G.; Peterson, D.; Filipski, A.; Kumar, S. MEGA6: Molecular evolutionary genetics analysis version 6.0. Mol. Biol. Evol. 2013, 30, 2725-2729. [CrossRef] 
57. Song, A.; An, J.; Guan, Z.; Jiang, J.; Chen, F.; Lou, W.; Fang, W.; Liu, Z.; Chen, S. The constitutive expression of a two transgene construct enhances the abiotic stress tolerance of chrysanthemum. Plant Physiol. Biochem. 2014, 80, 114-120. [CrossRef]

58. Sun, D.; Nandety, R.S.; Zhang, Y.; Reid, M.S.; Niu, L.; Jiang, C.Z. A petunia ethylene-responsive element binding factor, PhERF2, plays an important role in antiviral RNA silencing. J. Exp. Bot. 2016, 67, 3353-3365. [CrossRef]

59. Chen, C.; Chen, H.; He, Y.; Xia, R. TBtools, a Toolkit for Biologists integrating various biological data handling tools with a user-friendly interface. BioRxiv 2018. [CrossRef]

(C) 2020 by the authors. Licensee MDPI, Basel, Switzerland. This article is an open access article distributed under the terms and conditions of the Creative Commons Attribution (CC BY) license (http://creativecommons.org/licenses/by/4.0/). 